\title{
El pabellón de deseos. Co-creación y co-instalación artística para la mejora del espacio público
}

\author{
Bruno Sève ${ }^{1} \mid$ Ernest Redondo ${ }^{2}$ \\ Recibido: 02-04-2019 | en su versión final: 02-10-2019
}

\begin{abstract}
Resumen
Con el fin de crear un modelo de transformación urbana más inclusivo y sostenible, nuevos procesos de participación resurgen en los procesos urbanos de todo el mundo. Nuestra investigación estudia estrategias tanto tradicionales como nuevas para el proyecto urbano. Se plantean tanto herramientas enfocadas a las nuevas tecnologías de la información, como otras herramientas creativas tales como el urbanismo táctico. El principal objetivo de este artículo es evaluar el uso de talleres de co-creación y de urbanismo táctico, dentro de los procesos de diseño urbano. El uso de estos métodos no solo pretende ser una forma de escuchar la voz de la población, sino también de involucrarse como actores, induciendo un cambio en los hábitos y la mentalidad. El proyecto "Pabellón de deseos" es el resultado de una tercera experiencia del Taller Espacios Abiertos (TEA), con un grupo de estudiantes dentro del marco del Park(ing) Day, evento que transforma de forma temporal estacionamientos en la calle en otras formas de espacio público de convivencia. Este artículo aporta dos niveles de resultados: El primero consiste en los resultados y conclusiones de los datos recuperados mediante la instalación artística, imaginada por el cuerpo estudiantil, y el segundo, la evaluación del taller como herramienta participativa y pedagógica por parte del alumnado. Para obtener los resultados, se ha usado una evaluación tanto cuantitativa como cualitativa. Los resultados nos enseñan que la implementación de este tipo de talleres en un ámbito académico mejora la motivación, implicación y satisfacción en los procesos de proyectos urbanos.
\end{abstract}

Palabras clave: Participación; urbanismo pop-up; urbanismo táctico; bottom-up

Citación

Sève, B. y Redondo, E. (2020). El pabellón de deseos. Co-creación y co-instalación artística para la mejora del espacio público. ACE: Architecture, City and Environment, 14(42), 8200. DOI: http://dx.doi.org/10.5821/ace.14.42.8200

\footnotetext{
1 Arquitecto, Profesor asociado, Departamento de Representación Arquitectónica, Escuela Técnica Superior de Arquitectura de Barcelona, ETSAB-UPC (0000-0002-0600-1923), ${ }^{2}$ Dr. Arquitecto, Profesor Titular, Departamento de Representación Arquitectónica, Escuela Técnica Superior de Arquitectura de Barcelona, ETSAB-UPC (ORCID: 0000-0002-6633-4471; Researcher ID: A-3836-2013). Correo de contacto: bruno.seve@upc.edu
} 


\title{
The Pavilion of desires. Artistic co-creation for the improvement of public space
}

\begin{abstract}
In order to rebalance the city and create a more sustainable urban transformation model, new participation processes re-emerge in the urban and architectural processes in cities around the world. Our research studies both traditional and new strategies for the urban project. Both tools focused on new Information and Communication Technologies (ICT), as well as other creative tools such as tactical urbanism, are proposed. The main objective of this article is to evaluate the use of co-creation and tactical urban planning workshops within urban design processes. The use of these methods is not only intended as a way to listen to the voice of the population, but also to get involved as actors, inducing a change in habits and mentality. "Pavilion of desires" project is the result of a third experience of the Open Space Workshop (TEA), with a group of students within the framework of Park(ing) Day, an event that temporarily transforms parkings on streets in other ways of public living space. This article provides two levels of results: The first consists of the results and conclusions of the data recovered through the artistic installation, imagined by the student body, and the second, the evaluation of the workshop as a participatory and pedagogical tool by the students. To obtain the results, a quantitative evaluation using surveys and data collection was employed, as well as a qualitative evaluation through the use of general impressions, conversations, reports and level of participation in the workshop. The results teach us that the implementation of this type of workshop in an academic field improves motivation, involvement and satisfaction in urban project.
\end{abstract}

Keywords: Participation; pop-up urbanism; tactical urbanism; bottom-up

\section{Introducción}

\subsection{Paradigmas de planificaciones urbanas en el espacio público: Hacia una práctica participativa}

Los procesos de transformación urbana en el siglo XXI son cada vez más complejos y más rápidos. Dependen directamente de paradigmas de construcciones urbanísticas históricas. En Barcelona, con una larga tradición urbana, están documentados y estudiados por varios urbanistas, como Joan Busquets en su libro Barcelona. La construcción urbanística de una ciudad compacta (2004). En esta publicación, podemos, de manera cronológica, subrayar y resumir algunos "momentos paradigmáticos” de la construcción urbana: la formación histórica de la capital mediterránea medieval, encerrada en sus murallas; posteriormente, su desarrollo urbano hasta la industrialización, momento en cual la ciudad se desarrolla de manera planeada bajo la líneas directrices del plano Cerdá; la serie de eventos internacionales, verdaderos catalizadores de desarrollo urbano y de planeamiento urbano (Exposición Universal de 1888, Exposición de Industrias Eléctricas, Olimpiadas de 1992), lo que abrió la puerta también a cambios de escala metropolitana para la ciudad del siglo XXI post industrial; y más recientemente, los problemas ligados a la ciudad turística, como describe por ejemplo, el antropólogo Manuel Delgado (2007). Ya desde los años sesenta, se alzaba la voz de la vecindad en las grandes ciudades, como por ejemplo en París (Lefebvre, 1968/2007), por falta de equipamientos, espacios públicos de calidad para el vecindario, carencia de vivienda pública, falta de consideración de la opinión pública y otras deficiencias que desencadenan las luchas urbanas. En Barcelona, esta respuesta al conflicto urbano se canaliza 
principalmente a través de las asociaciones de barrios, con el soporte de algunas prensas, colegios profesionales y otras entidades ciudadanas. Aquellos movimientos sociales urbanos (MSU), en algunos casos han podido transformar o proteger algunos espacios urbanos amenazados por planificaciones urbanas drásticas (Domingo i Clota y Bonet i Casas, 1998).

En cuanto a sus espacios públicos y a la temática de la movilidad, y, más concretamente el Eixample, el distrito más poblado de la ciudad (266.416 habitantes en 2017)1', Barcelona sufre todavía de un mal persistente, como numerosas otras ciudades del mundo: un tráfico contaminante y un espacio público degradado por el mismo. Como comenta el urbanista Jan Gehl, y siguiendo la temática, existen dos grandes paradigmas de ordenación urbana en los centros de las ciudades estos últimos cincuenta años: el movimiento moderno y la invasión de los coches. La ciudad "moderna", aunque aparentemente perfecta desde una visión aérea con espacios muy bien delimitados, contrasta con la visión a pie de calle. Al proyectar edificios individuales y de mayor escala cada vez más grandes, siguiendo el famoso afán de "la forma sigue a la función", la noción de la escala humana desaparece totalmente (Gehl y Svarre, 2013). Aunque se refiere a ese efecto como el síndrome de Brasilia, y concretamente al movimiento moderno, no se puede dejar de pensar entonces en el famoso Eixample de Barcelona, con su trama ejemplar vista desde el cielo, que contrasta con sus calles actualmente invadidas por los vehículos a motor. Esta situación lamentable en el espacio público, del centro de Barcelona, depende directamente de dinámicas metropolitanas que provienen de dos modelos de ciudad contrapuestos, que existen en la región metropolitana de Barcelona: por un lado, el modelo del centro urbano, ciudad compacta, con la apuesta de una ciudad densa con espacios urbanos continuos, con una alta utilización de sus calles y plazas, con funciones mixtas, etc., y por otro lado, la periferia metropolitana, con bajas densidades, una discontinuidad en los tejidos urbanos, y zonificación funcional. Esto se traduce en un uso mayor del transporte privado en la periferia (con un total de 48,9\% de transporte privado) contra un uso menor en el área central (22,1\%) (Miralles-Guasch C., 2011).

En respuesta al fenómeno de invasión de los autos, que es similar en otras ciudades, se están probando varias estrategias desde hace décadas. Por un lado, mejorando la oferta de transporte público hacia el área central y por otra parte limitando la oferta para los vehículos privados en el centro con el fin de recuperar el espacio público para un uso cívico y una movilidad sostenible, creando calles y ejes pacificados. El objetivo es proseguir y proponer un círculo virtuoso donde se cambie el reparto modal poco a poco (porcentaje de viajeros que usan un modo de transporte) para que tienda siempre hacia una movilidad más sostenible. Este cambio consiste en hacer que gran parte de la población que circula hoy en vehículos motorizados vayan mañana en transporte público, bicicleta (clásica o eléctrica) o caminando, actuando directamente sobre el espacio público (vial y peatonal) físico que existe. Es decir, si cambiamos una vía de tráfico o una línea de estacionamiento en la calle por una doble vía de bicicleta, bajamos la oferta para vehículos motorizados mientras aumentamos la oferta para las bicicletas. El cambio modal se hace entonces a medida que transformamos el espacio público. Al menos teóricamente. El problema es que, hasta ahora, algunos proyectos de reordenación urbana ambiciosos cambian radicalmente el entorno urbano, favoreciendo la llamada gentrificación, sin tener en cuenta el tejido social del barrio. Estos proyectos no consideran lo suficiente la aceptación de estos proyectos por parte de la ciudadanía, ni tampoco su falta de implicación, y suelen marginalizar a la población local e incluso excluirla.

Quizás se trate entonces de actualizar aquel modus operandi, y al hacerlo, inaugurar un nuevo paradigma de planificación urbana, en el cual las personas participantes pueden codiseñar el proyecto y además con el cual conseguimos crear una educación ambiental. Uno de estos métodos puede ser la integración de dinámicas performativas, instalaciones co-construidas que permiten una aceptación y una transformación paulatina del espacio público. Se trata por supuesto de un equilibrio difícil de encontrar y que, por supuesto depende también de otros factores jurídicos y

\footnotetext{
${ }^{1}$ Según IDESCAT (Instituto de Estadística de Cataluña (https://www.idescat.cat).
} 
políticos, que no abordaremos demasiado, como los controles de los alquileres, o la cantidad de vivienda social. Volver a mirar a la ciudad desde las personas, en vez de una problemática infraestructural, es un concepto relativamente nuevo, ya defendido en New York por Jane Jacobs, con las luchas vecinales en los años 50². Pero, como apuntan Zaida Muxí Martínez y Blanca Gutiérrez Valdivia (2011), “los problemas, las amenazas que Jane Jacobs veía en la dispersión territorial, en la segmentación de usos, en la primacía del vehículo privado, en la destrucción de barrios para la modernización de la ciudad, en la inseguridad derivados de los usos segregados siguen siendo similares." (Muxí Martínez y Gutiérrez Valdivia, 2011, págs. 7-8)3 Nacen hoy nuevos tipos de planeamientos desde la visión cotidiana de la ciudadanía, como por ejemplo el reciente Plan de Barrios ${ }^{4}$, iniciado por el Ayuntamiento de Barcelona en 2016 y actualmente en curso. Nuevos equipos locales trabajan ya desde hace más de una década sobre la cuestión, como, por ejemplo, los trabajos del Col-lectiu Punt 6 (2014, 2014a, 2017, 2017a) y Zaida Muxí, que trabajan desde una perspectiva de génerO ${ }^{5}$, Raons Públiques y La Col, con sus actividades participativas, que construyen su diagnóstico y especificaciones urbanas a partir de la experiencia de la ciudadanía ${ }^{6}$. Parece claro que los métodos de co-creación y de educación ambiental son una clave para un urbanismo más democrático: crear la ciudad no solo para la gente, sino con la gente.

\subsection{People versus Cars: pruebas tácticas y acciones participativas en el espacio público}

Adaptar el espacio público en los centros urbanos es necesario por varias razones. Primero de todo, por la contaminación: según el Ayuntamiento de Barcelona, 500.000 vehículos entran cada día a Barcelona. A esta cifra están asociadas 3.500 muertes prematuras, 31.000 bronquitis infantiles y 54.000 ataques de asma7. Dicho de otra manera, 5 vehículos entrando en Barcelona generan 1 enfermo cada año. Ya es una cuestión de salud pública. Podemos mencionar el experimento en curso de Barcelona Life Study Cohort', bajo la coordinación del Institut de Salut Global de Barcelona, que estudia cómo afecta la contaminación atmosférica en la salud de los bebés y su desarrollo cerebral, incluso desde antes del nacimiento. Según otro estudio de IS Global para el Ayuntamiento de Barcelona, durante el día sin coches en Barcelona en 2018, la pacificación del cruce de Tamarit - Comte Borrell, en el barrio de Sant Antoni, redujo un 67\% la contaminación ambiental (Ayuntamiento de Barcelona, 2018).

La segunda razón es el desaprovechamiento del espacio público. Varios estudios muestran que una persona en coche ocupa unos diez metros cuadrados, una o un ciclista poco más de un metro cuadrado, y una o un usuario del bus la mitad de un metro cuadrado. Vamos a fijarnos en el

\footnotetext{
2 Jacobs luchó en los 50 para evitar que Washington Square Park fuese demolido por la extensión de la quinta avenida, proyecto propuesto por Moses.

${ }^{3}$ En el prólogo, titulado Apuntes sobre Jane Jacobs, del libro Muerte y Vida de las grandes ciudades (Jacobs, 1961), las autoras (Zaida Muxí Martínez y Blanca Gutiérrez Valdivia) explican como las principales ideas de la famosa urbanista siguen vigente. Subrayan además Jane Jacobs como defensora de "otra planificación", desde la experiencia cotidiana y necesidades de las personas.

${ }^{4}$ Para más información: http://pladebarris.barcelona/es.

5 Para más información, ver las guías elaboradas por el Collectiu Punt 6 sobre los entornos habitables (http://www.punt6.org/guias-propias-de-collectiu-punt-6/) y Muxí, 2008.

${ }^{6}$ Sobre este tema, el lector encontrará varios equipos locales en el libro editado por La Col, Construir en Colectivo, con casos de estudios y métodos.

${ }^{7}$ Según un artículo de El Periódico, [en línea], “La contaminación atmosférica causa 3.500 muertes anuales en el área metropolitana, según un estudio, 2009. "El alto nivel de partículas contaminantes en el aire de los 57 municipios que conforman el área metropolitana de Barcelona, que duplica el volumen aconsejado por la OMS, provoca cada año 3.500 muertes, según un estudio del Centro de Investigación en Epidemiología Ambiental (CREAL)...”. El CREAL ha advertido de que también disminuirían en 1.800 los ingresos hospitalarios por causas cardiorrespiratorias en un año, se producirían 5.100 casos menos de bronquitis crónica en adultos, 31.100 casos menos de bronquitis aguda en niños y 54.000 crisis asmáticas menos en el conjunto de la población...”.

${ }^{8}$ Para más información: https://www.isglobal.org/-/bisc-barcelona-life-study-cohort-\#
} 
Eixample, donde el espacio público está altamente acotado en vastas superficies para el uso exclusivo del automóvil, en detrimento de peatones, peatonas y habitantes. Si miramos el caso de un cruce típico de esta zona, con sus chaflanes, como tantos hay en Barcelona (Figura 1), podemos determinar que un 75\% del espacio (el cruce de asfalto) está dedicado a los vehículos motorizados, mientras solo unos 25\% (la acera) quedan para las personas que van a pie (sin contar las motos aparcadas que ocupan gran parte de este espacio). No cabe duda que este espacio es cuando menos desagradable y antes o después este modelo debe cambiar.

Figura 1. Desaprovechamiento del espacio público en un cruce del Eixample
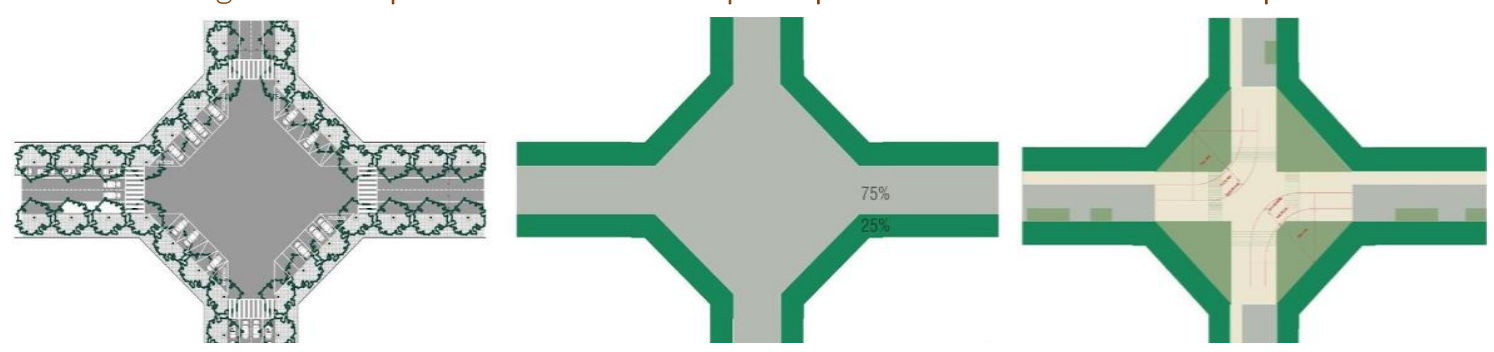

Fuente: Elaboración propia.

Con el nuevo plan de movilidad (2013-2018), el Ayuntamiento de Barcelona está apostando ahora por la creación de supermanzanas, con operaciones piloto en Poble Nou y en Sant Antoni. Si bien aparentemente, la experiencia es un éxito y tiene futuro, algunas reacciones negativas (pancartas de "No Superilles") y una petición firmada con más de 3222 personas", demuestran todavía carencias en el modo de participación de estas experiencias. David de la Peña, profesor en la Universidad de California y especialista en participación urbana, autor del libro Design as Democracy, comenta de hecho en un post de su blog, que el éxito de la supermanzana y de su proceso participativo es controvertido: "For those familiar with how citizen participation works in Barcelona, the failure of participatory process is all too familiar. In the "City of Architects," expert designers know best, and design cities and spaces "for the people" but aren't comfortable designing "with the people..." (Peña, 2016). Sin entrar en el debate, y aceptando que la ciudad de Barcelona ha mejorado últimamente de manera significativa sus procesos participativos, cabe sin embargo recordar la importancia de este tipo de experiencias de co-diseño, de performance y de ocupación del espacio que permiten generar un interés real, de valor ambiental, pero que siguen siendo efímeras hasta su asimilación por la mayoría de la población. Así pues, no se trata tanto de la supermanzana o de una transformación del espacio público que se recupera, por ejejemplo, cambiando hileras de estacionamiento por espacios verdes o carriles bici, sino que se trata de hacerlo contando con la población. En este sentido, podemos observar varias experiencias en el espacio público, en ocasiones olvidadas, pero claramente participativas, y que sirven de base a este artículo.

Una de las experiencias de performance efímero participativo en el espacio público más interesante, para educar y reivindicar el espacio público es la comisionada por la oficina de planificación de la Ciudad de Münster en 1991, que se hizo durante los días de la bicicleta "Fahrradtage" (Bikehub, 2012). Participaron más de 72 personas en aquel evento, en el cual se tomaron fotografías del espacio necesario para transportar aquellas personas tanto en coche, bus o bicicleta (Figura 2). El lugar escogido para las fotografías fue en unas de las calles más emblemáticas, la Prinzipalmarkt, que significa mercado principal, por su antigua función histórica. Fue y es todavía también un lugar estructural del centro económico y político de Münster. Hoy en día, la ciudad de Münster está considerada como la capital de las bicicletas, y contaba en 2013 con más de 460 km de carriles bici. El panel tríptico de 1991, que giró alrededor del globo, enseña el malgasto del espacio para los automóviles. Unos conceptos que ya habían sido comentado por el filósofo austriaco Ivan Illich (Illich, 1978).

\footnotetext{
${ }^{9}$ Ver web change.org: https://www.change.org/p/ajuntament-barcelona-no-a-la-superilla-del-poblenou
} 


\section{ACE Architecture, City and Environment}

Figura 2. Fotografía de la experiencia de Münster
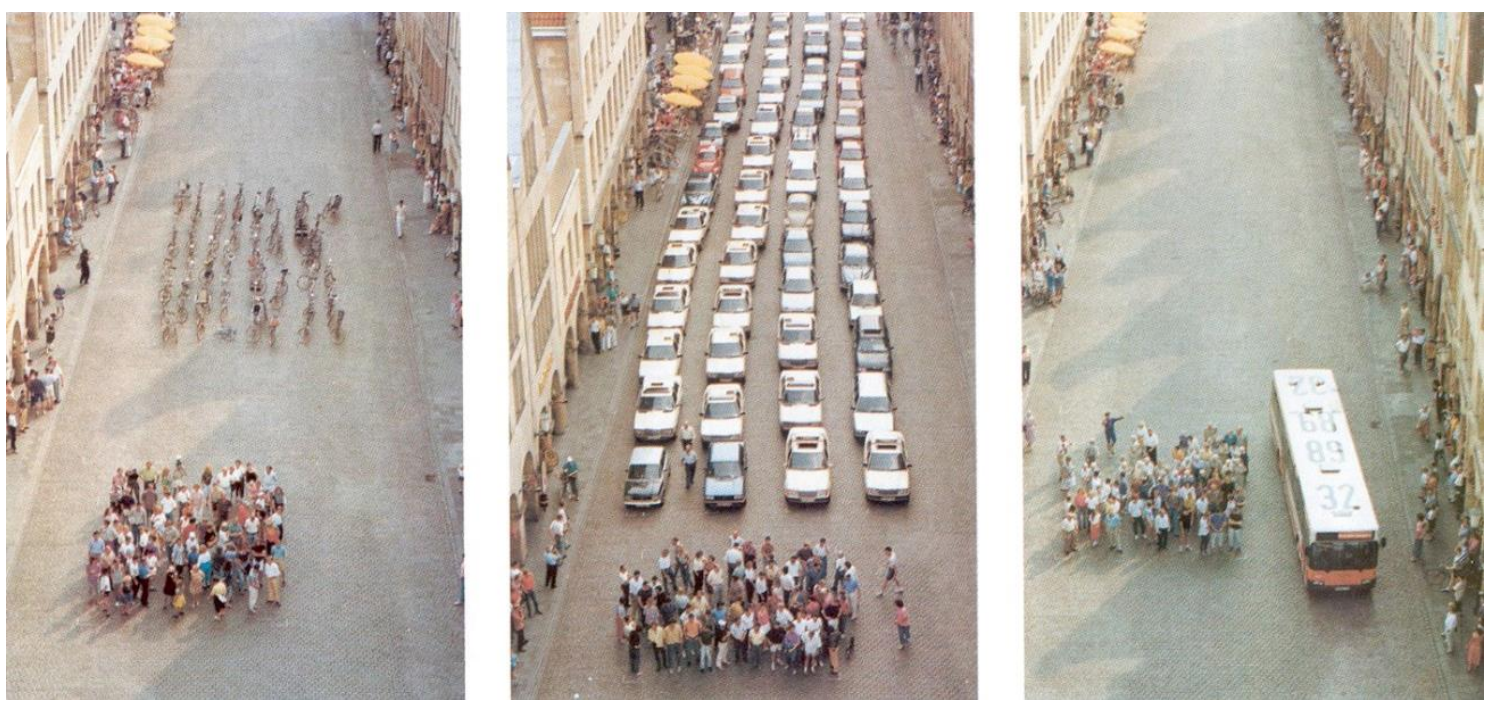

Fuente: Oficina de planificación de la Ciudad de Münster.

Desde que los carteles de Münster se volvieron famosos, otras variantes de las tres fotografías tuvieron lugar como en Reikiavik, Islandia el 19 de junio 2010 con la participación de 70 personas ${ }^{10}$, en Canberra, Australia, el 9 de septiembre 2012, organizada por Cycling Promotion Fund con 69 participantes, 69 bicicletas, 60 coches y un bus ${ }^{11}$. En aquellas experiencias, el uso de grabaciones en vídeo permitió entender el modo de acción, con el uso respectivamente de un camión de bomberos y una grúa para la sesión de fotografía. Otra versión alternativa de 2015, organizada por una consultoría sostenible International Sustainable Solutions, en Seattle, se encuentra en la red en diferentes formatos, incluso en un formato de GIF (Graphics Interchange Format), realizado por el Washington post para Wonkblog (Swanson, 2015) enseñando un escenario ligeramente diferente con 200 viajeras y viajeros en 177 coches, bicicleta, tres autobuses o un tranvía. Otra evolución del concepto interesante del desaprovechamiento del espacio es la demostración que tuvo lugar en Riga, Letonia, en la cual los y las ciclistas, vistieron las bicicletas con una "armadura" representando el espacio del automóvil.

Otro criterio en las demostraciones en el espacio público, es el del tiempo de recorrido, en relación con las congestiones de tránsito de algunas ciudades. En el ámbito del Urbanismo, los mapas isócronos, se utilizan comúnmente para describir las áreas de igualdad de tiempo de viaje, comparando en los diferentes modos de transporte, por ejemplo, a pie, en bicicleta. Actualmente, con la emergencia de los datos abiertos, con la utilización de API de Google Maps, u Openstreet map, como mapumental o mapnificient, es posible comparar aquellos viajes cambiando de modelo. En un ámbito más participativo y demostrativo, existen por ejemplo experiencias en México como la llamada Desafío modal, en la cual colectivos de ciclistas evalúan la eficiencia de las formas de moverse en la ciudad, mediante una simulación de una situación de traslado de un origen a un destino con diversas formas de locomoción y diferentes rutas. En 2018, aquel evento se desarrolló en 23 ciudades mexicanas, en un único día del año, y fue organizado por la Red Nacional de Ciclismo Urbano de México (WWF, 2018). Los resultados de aquella prueba en la Ciudad de México, a hora punta (8h34) revelaron que la bicicleta, los patines y la motocicleta son más eficientes que el automóvil, con una diferencia de más de 24 minutos entre la bicicleta y el automóvil. Resultados similares se dieron en otras ciudades, como en Oaxaca de Juárez, también en hora punta (7h30), donde cada participante grabó su ruta en el móvil a través de una aplicación, con unas rutas

\footnotetext{
${ }^{10}$ [StudGM], 2010

${ }^{11}$ [AustDoc], 2012
}

ACE, 14. (42) CC BY-ND 3.0 ES | UPC Barcelona, España | El pabellón de deseos. Co-creación y co-instalación artística para 
escogidas propias. En el caso oaxaqueño (Tabla 1), la bicicleta llegó con 15 minutos de antelación respecto al automóvil (21 minutos contra 36 minutos) $)^{12}$.

Tabla 1. Resultados del desafío modal en la ciudad de Oaxaca de Juárez, México

\begin{tabular}{|c|c|c|c|}
\hline Medio de transporte & Duración & Distancia $(\mathrm{Km})$ & Precio $(\mathbf{\$ M X N})$ \\
\hline Bicicleta & $00: 21$ & 5,00 & 0,00 \\
\hline Bicicleta & $00: 22$ & 6,10 & 0,00 \\
\hline Motocicleta & $00: 24$ & 5,17 & 3,47 \\
\hline Motocicleta & $00: 27$ & 6,70 & 5,24 \\
\hline Autobús & $00: 36$ & 6,00 & 15 \\
\hline Moto taxi + Autobús & $00: 36$ & 6,00 & 15 \\
\hline Automóvil & $00: 36$ & 7,20 & 18 \\
\hline Varios & $00: 36$ & 6,10 & 0.00 \\
\hline Caminando & $00: 56$ & 3,20 & 18 \\
\hline
\end{tabular}

Fuente: Pascal Rastoul y el colectivo de ciclista Oaxaca (COCO), Ciclistas se lanzan en el Desafío Modal, Boletín de prensa del jueves 20 de septiembre 2018.

Otras experiencias en curso que cabe mencionar, ya que se inscriben en el mismo marco relacionado con la participación y los medios de información y comunicación, es la de la realidad virtual aplicada a la transformación urbana (Sánchez-Sepúlveda, Fonseca, Franquesa, Redondo, 2019). Esta tecnología, que fascina actualmente la imaginación popular y que está estudiada por numerosos investigadores, tiene una aplicación especialmente interesante en el marco de la participación. En este caso, la transformación espacial y el método de prueba, aunque virtual, es totalmente válido, ya que permite al participante experimentar una nueva forma de ocupar el espacio e interactuar con este, aunque sea virtualmente. La aplicación de la realidad virtual fue en un proyecto urbano, promovido por el Ayuntamiento de Barcelona, relacionado con la creación de un gran espacio público para la pacificación de las calles y la aplicación de supermanzanas. La experiencia participativa consistió entonces en la creación de un juego de realidad virtual, en el cual los participantes pueden dar forma al espacio público urbano. Se utilizaron tecnologías portátiles ("wearable" tech.) con gafas y tabletas de realidad virtual. Una de las características interesantes fue que las personas participantes pudieron ver lo que proponían en tiempo real, jugando realmente con el entorno, cambiando el mobiliario o la vegetación de sitio, cambiando el entorno de día a noche, etc. (Figura 3).

Figura 3. Realidad virtual aplicada a la transformación urbana digital

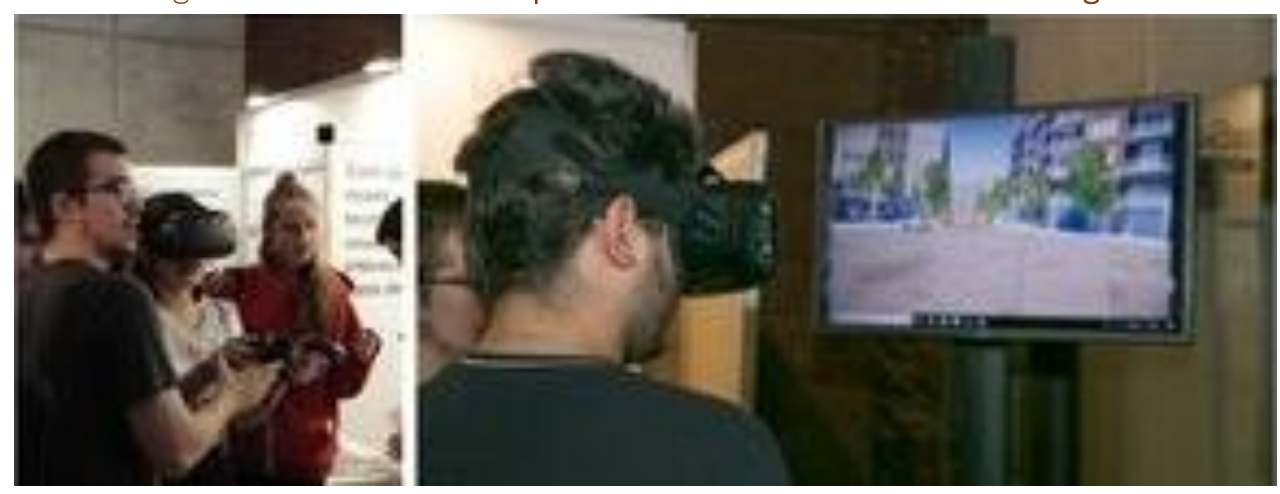

Fuente: https://recercaensocietat.wordpress.com/galeria-multimedia/

\footnotetext{
12 Pascal Rastoul y el colectivo de ciclista Oaxaca (COCO), Ciclistas se lanzan en el Desafío Modal, Boletín de prensa del jueves 20 de septiembre 2018.
} 


\section{El Taller Espacios Abiertos}

\subsection{Definición y experiencia previa}

El Taller Espacios Abiertos es un taller de co-creación, en el cual las personas participantes generan una suma de ideas y conceptos, y formalizan un diseño artístico y una respuesta a la resolución de un problema a escala 1:1. Se trata de un proceso alternativo que parte de situaciones urbanas orientado no solo a estudiantes de arquitectura, diseño y arte, sino a cualquier persona interesada en mejorar su entorno urbano. Supone la oportunidad de reunir diferentes personas involucradas en un espacio urbano. En general, las instalaciones generadas por los talleres a escala 1:1 (bricolaje urbano) no sirven como uso definitivo de un espacio, sino que pretenden captar ideas y reforzar comunidades. Estos talleres suelen reivindicar espacios abandonados o desaprovechados ${ }^{13}$. En la experiencia previa, llamada "TEA: Recicla el ferrocarril", el tema del taller no estuvo relacionado con la movilidad, sino con la reconversión de unos espacios ferroviarios obsoletos y abandonados en espacios culturales, en la ciudad de Oaxaca de Juárez, México. Este taller, que duró 8 meses, reunió a un grupo de estudiantes y personas vecinas cercanas, donde surgieron ideas para resolver algunos problemas urbanos y sociales. El trabajo del alumnado supuso la reconversión de cinco vagones de tren abandonados en espacios cívicos para la población (sala multimedia, ludoteca, salas polivalentes para cursos y talleres) y prototipos de mobiliario urbano. Aunque las instalaciones fueran efímeras, manifiestan ideas sostenibles y nuevas prácticas urbanas que las autoridades democráticas deben asimilar.

A posteriori, el gobierno junto con algunas fundaciones, continuó parcialmente la transformación de los espacios y los mejoró. ${ }^{14}$ Aunque la duración y el tema principal de los dos talleres son distintos, el modus operandi es similar, con una fase teórica, de co-creación y de intervención en el espacio urbano. En las dos experiencias presentadas en este artículo, hemos concebido una herramienta de retroalimentación sobre la participación de los estudiantes, para entender cuáles son los puntos positivos del taller. Una comparación escrita y gráfica (Figura 12) ilustra los resultados, que valoran y comparan los dos talleres.

Figura 4. Taller Espacios Abiertos: recicla el ferrocarril
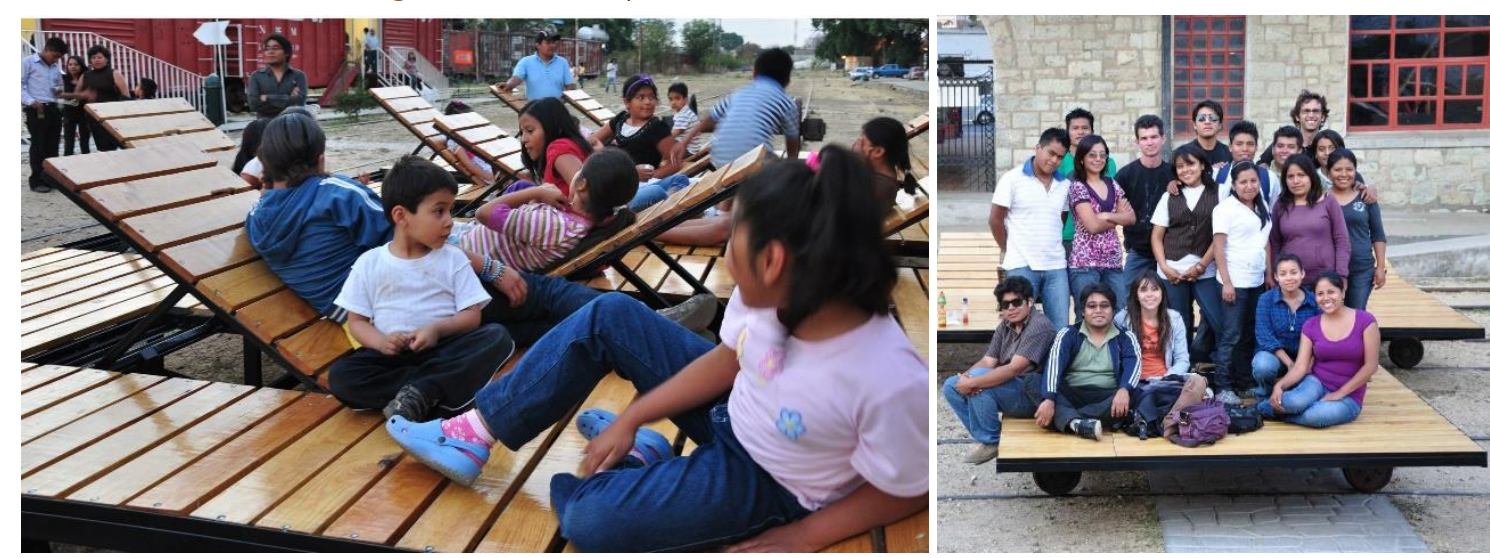

Fuente: elaboración propia.

\footnotetext{
13 A imagen y semejanza de colectivos, arquitectos y arquitectas como Walter Segal, Doina Petrescu, Santiago Cirugeda, Arquitectura Expandida, Rebar, Ya+K, Makea, etc.

${ }^{14}$ Ver el MIO, museo infantil de Oaxaca.
} 


\subsection{El pabellón de deseos y el Park(ing) Day 2018}

En el marco de la semana de la movilidad sostenible promovido por el Ayuntamiento y del Park(ing) Day 2018, propusimos una nueva experiencia del Taller Espacios Abiertos, taller de co-creación y co-construcción participativo con estudiantes de la ETSAB con varios objetivos.

El Park(ing) Day es un evento anual abierto a la participación de la ciudadanía que consiste en transformar, durante un día, una plaza de aparcamiento en un jardín efímero o en otro uso temporal. Se celebra en diversas ciudades en todo el mundo con el objetivo de reivindicar más parques, zonas verdes y una movilidad sostenible. Durante un día, diferentes entidades y colectivos, transforman temporalmente una serie de plazas de aparcamiento en otro tipo de espacios públicos. El evento inició en San Francisco por Rebar Art and Design Studio, llamado REBAR1 ${ }^{15}$, que operan a la intersección entre arte, diseño y activismo. Con la ciudad de San Francisco, también han lanzado GroundPlay ${ }^{16}$, continuación del Park(ing) Day intervención en urbanismo táctico y la continuación del Park(ing) Day.

En el evento de 2018 en Barcelona, 40 instalaciones han ocupado y transformado la ciudad en un total de 64 estacionamientos públicos, el equivalente a $812 \mathrm{~m} 2$.

En nuestro caso, el interés reside a dos niveles: El primer nivel (N1) es su evaluación como herramienta participativa y su interacción con la ciudadanía. El segundo nivel (N2) consiste en la aplicación de este tipo de workshop en las escuelas de Arquitectura, su congruencia pedagógica, su participación académica, para una aplicación más importante en el curso de la carrera de arquitectura, urbanismo y paisajismo. En estos dos niveles, se ha optado por una evaluación mixta, usando tanto datos cuantitativos como cualitativos, lo que nos permite identificar los aspectos de una manera objetiva. En este sentido, esta experiencia se consolida del taller previo desarrollado en México, que ha sido evaluado de la misma manera por el alumnado, con la misma encuesta.

Los objetivos principales de este artículo a través de los datos recopilados son:

- Crear una actividad artística participativa en el espacio público, transformando de manera efímera algunos estacionamientos en el marco del Park(ing) Day.

- Evaluar el taller de co-creación como herramienta de participación estudiantil: Fomentar la interacción entre los ciudadanos y los estudiantes.

- Sensibilizar a la ciudadanía sobre el desaprovechamiento del espacio urbano y sobre nuevas formas de movilidad ecológica.

- Recolectar información sobre: la opinión del estado actual y los deseos de futuro para espacios urbanos del Eixample y Barcelona.

(N2)

- Evaluar el taller de co-creación como proceso pedagógico en las escuelas de Arquitectura, con un caso concreto de problem-solving. Crear una actividad artística y participativa para el cuerpo estudiantil con un enfoque social y ecológico, en una visión transversal, en la cual las y los estudiantes abordarán varias temáticas y materias: ecología, urbanismo, arquitectura, estructuras, gestión de la intervención (transporte, economía), aprendizaje a través del empirismo y la experimentación.

\footnotetext{
15 Más información en: https://www.linkedin.com/company/rebar-art-and-design-studio

${ }^{16}$ Más información en: https://groundplaysf.org
} 
- Retar al alumnado a proyectar en un tiempo récord una instalación artística y arquitectónica a escala 1/1, con un concepto claro y sencillo entendible por la ciudadanía. En este sentido, el trabajo en grupo se hizo semejante a las asambleas, con decisiones tomadas de manera consensuada, alejándose del modelo competitivo (como por ejemplo el concurso) de la arquitectura actual.

- Promover la sostenibilidad, los procesos circulares y la ecología en todos los aspectos del taller: movilidad sostenible, materiales recuperados o reciclados, sostenibilidad comunitaria, cohesión social en la comunidad estudiantil, etc.

- Vincular la Universidad con proyectos urbanos concretos y actuales dentro de la Ciudad de Barcelona.

Figura 5. El pabellón de deseos
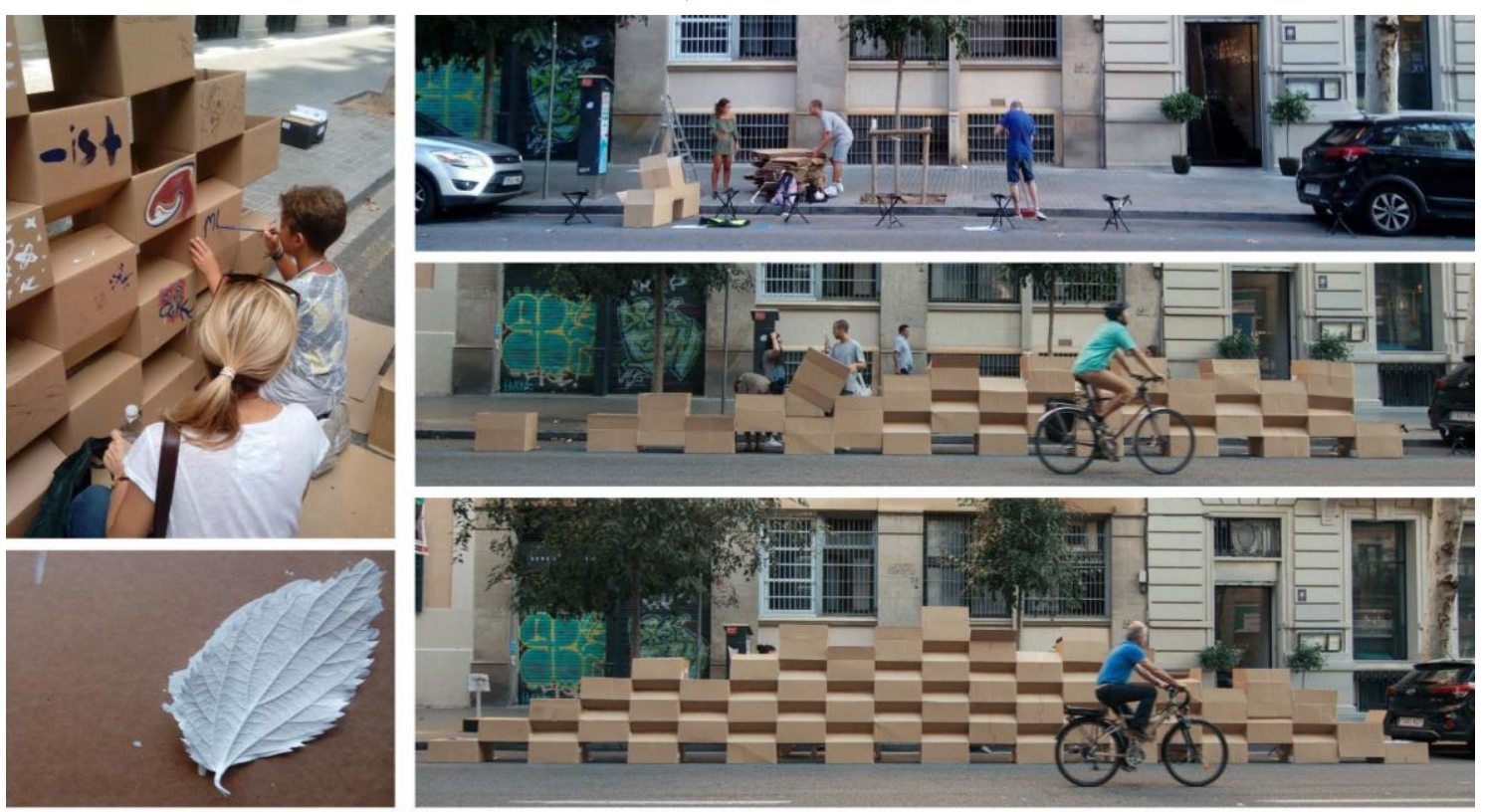

Fuente: Fotografías izquierda: elaboración propia y derecha: Carolina Triches.

\section{Resultados}

\subsection{Desarrollo del Taller de co-creación}

El Taller de co-creación se desarrolló en un tiempo acotado (5 días). La primera sesión consistió en una presentación a las y los 12 estudiantes del evento relacionado con el Park(ing) Day, con varias temáticas como la sensibilización sobre el problema del mal uso del espacio público en detrimento de la población, enunciados de conceptos básicos de urbanismo sostenible, co-diseño y pop-up urbanism, instalaciones artísticas en el espacio público y otras dinámicas participativas en grupo. Esta presentación inicial es necesaria para poder informar de manera adecuada a las personas que participaron al proyecto. Una segunda actividad consistió en mesa redonda y design thinking.

En el centro de las mesas se colocó unos cartones recuperados con varios rotuladores y marcadores para poder dibujar, apuntar y expresarse de forma colectiva. Se desarrolló entonces una lluvia de ideas para los conceptos iniciales y la búsqueda de materiales recuperados para la instalación. Con el apoyo del profesorado, se apuntaron en la pizarra las conclusiones, palabras claves y conceptos iniciales de esta primera sesión. El día siguiente, se invitó al alumnado a visitar el lugar para la instalación sobre 3 estacionamientos, ubicado cerca del Arco del Triunfo en el cuadrante de oro de l’Eixample. 
El siguiente taller consistió en la experimentación con los materiales recuperados a escala 1:1 en las aulas de la ETSAB, en este caso cajas de cartón recuperadas de varias universidades de la UPC, y sus posibilidades estructurales, con pliegues y encastramiento y sin ninguna necesidad de adhesivo exterior. Con el fin de dinamizar y acceder a más información, la mesa redonda se dividió en dos grupos para profundizar en los conceptos. En esta primera actividad, el objetivo es el de concebir una estructura espacial, omitiendo por un momento las bases conceptuales del primer día. Acotando esta primera actividad en una sesión de una hora, las y los estudiantes están invitados a volver a reflexionar sobre los conceptos iniciales. De esta manera, el pabellón de deseos nace de dos ideas previas, un espacio de reflexión, aislado de alguna manera del contexto urbano y el árbol de deseos, que surgieron del primer día: La propuesta consiste en un espacio que invita a la ciudadanía a pensar sobre el futuro de Barcelona, y más exactamente enfocado en la temática del espacio público, con una pregunta simple: ¿cuál es su deseo para el espacio público de la Barcelona del futuro?

Al entrar, el público encuentra varios medios artísticos, como rotuladores, pinturas recuperadas de obras, para dejar libre su expresión de deseos. El objetivo es la creación de un espacio cambiante, efímero, que se rellena y se reescribe a la manera de un palimpsesto, como la ciudad misma que se transforma con el tiempo. Los deseos serán recopilados y analizados a través de fotografías. El día siguiente, el alumnado tuvo que ingeniar maneras de transportar los materiales con mochilas adaptadas hasta un lugar prestado por vecinas del barrio.

Finalmente, uno de los aspectos interesantes relacionados con el día del Park(ing) Day, es el hecho que uno tiene apropiarse de las plazas de estacionamientos. Aquel día, las autoridades autorizan el evento reivindicativo dentro del marco de la Semana Europea de la movilidad, pero sin reservar y sin perímetro de seguridad. Fomenta el aspecto demostrativo, reivindicativo y de organización en grupo. El grupo se organizó para "ocupar" dos estacionamientos muy temprano por la mañana, a las 7h30, montando un desayuno in-situ. Para la construcción del pabellón, se necesitaron 99 cajas grandes de cartón, 13 medianas y 56 pequeñas, rollos de plotter de dos medidas diferentes, cajas de fruta usadas, palés, cinta de pintor, pintura, rotuladores usados y libros prestados por unas vecinas para actuar como contrapeso en los muros. La autoconstrucción del pabellón se desarrolló en un ambiente relajado, con comida y música improvisada, y se prolongó durante dos horas y media. A lo largo del día, el alumnado invitó al público que paseaba a dialogar y expresar sus deseos en las paredes del objeto insólito. La experiencia fue a partir de este momento artística e interactiva, en la cual participaron vecinas y vecinos, transeúntes, turistas, etc. A medida que las paredes del pabellón se iban llenando, más participantes acudían, mostrando su curiosidad por participar. El evento acabó de noche con el reciclaje de la estructura.
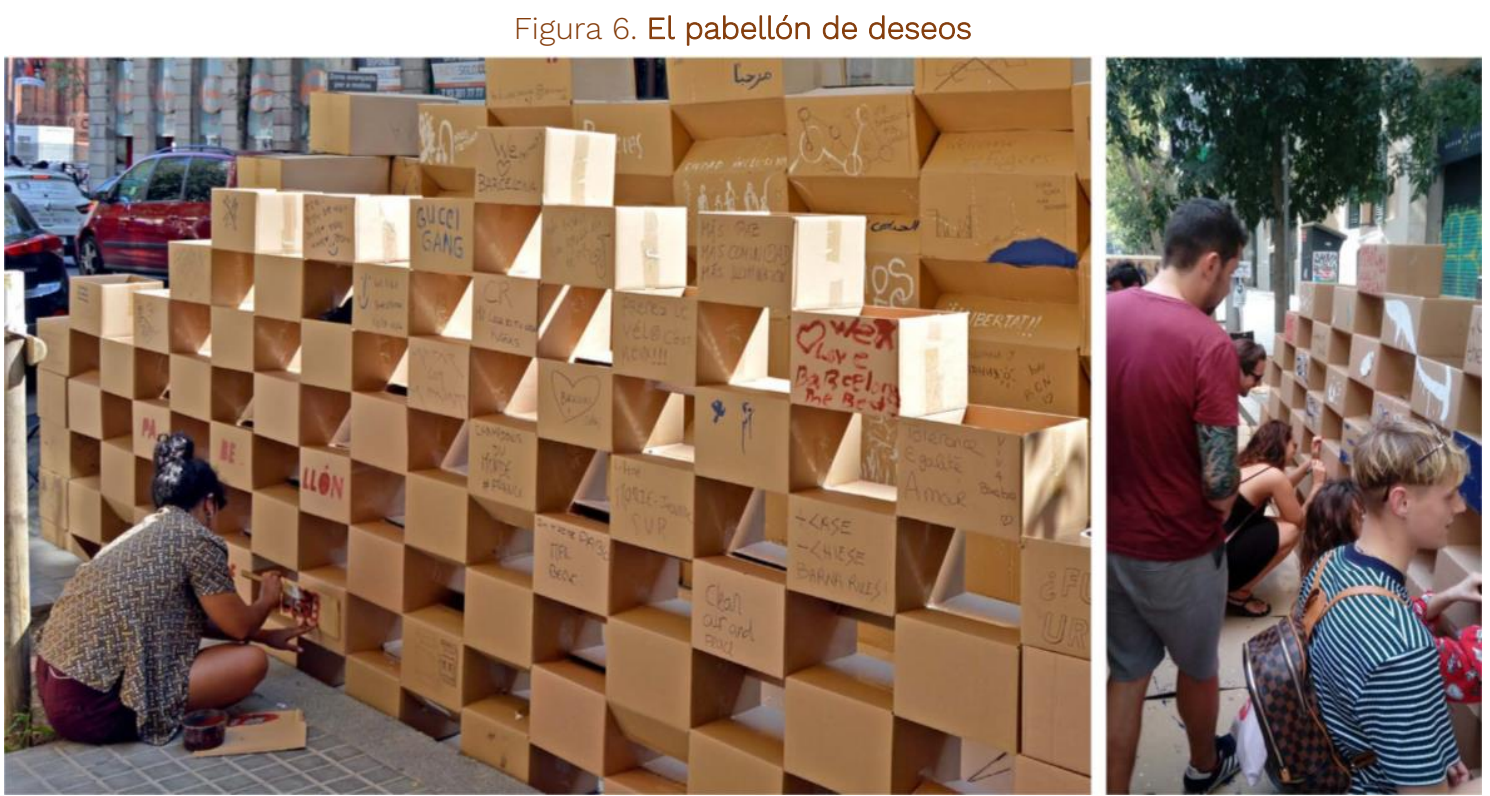

Fuente: Fotografía izquierda: Paula Mourenza y fotografía derecha: elaboración propia. 
Por otra parte, hemos podido superponer a esta primera observación cualitativa datos cuantitativos. Los deseos participativos de los visitantes (N1) fueron registrados con la fotografía de los deseos pintados en las paredes del pabellón. A continuación, se ilustra y se explica cómo el alumnado clasificó los deseos y generó resultados convincentes. El pabellón estuvo accesible desde las 10h de la mañana hasta las $20 \mathrm{~h}$ de la tarde, con el fin de conseguir una interacción máxima y diversa de participantes: Turistas, personas vecinas, habitantes, trabajadores, etc. Se recogieron, a la imagen de un registro taxonómico, en formas de etiquetas ${ }^{17}$, los deseos de la siguiente manera:

N1-1 - Sustainability and Ecology,

N1-2 - Creation, artistic, expression space,

N1-3 - Community and social inclusion,

N1-4 - Not relevant

De manera general, se registraron más de 150 mensajes en las paredes, y se estima que pasaron por este más de 200 personas desde las 8h de la mañana en un ambiente festivo y agradable. Aunque la implantación de la instalación fue céntrica -cerca del Arco de Triunfo- la participación fue mayoritariamente local, con 79 mensajes en castellano y catalán, 38 en un idioma extranjero, mientras 33 mensajes fueron representaciones artísticas (Figura 8).

La mayor preocupación de las personas participantes fue por imaginar una ciudad más sostenible y ecológica, con un 45,3\% de mensajes y algunos mensajes muy explícitos, descritos a continuación, mientras que a 34,7\% les gustaría imaginar más cohesión, convivencia social y sentimiento de comunidad. Finalmente, de manera sorprendente, el pabellón de deseos fue fuente de inspiración: el 12,7\% de los mensajes reivindicaron más espacios de creación artística y expresión, como este mismo, en la ciudad, para poder opinar, crear, expresarse e interactuar.

\section{Figura 7. Algunos deseos}
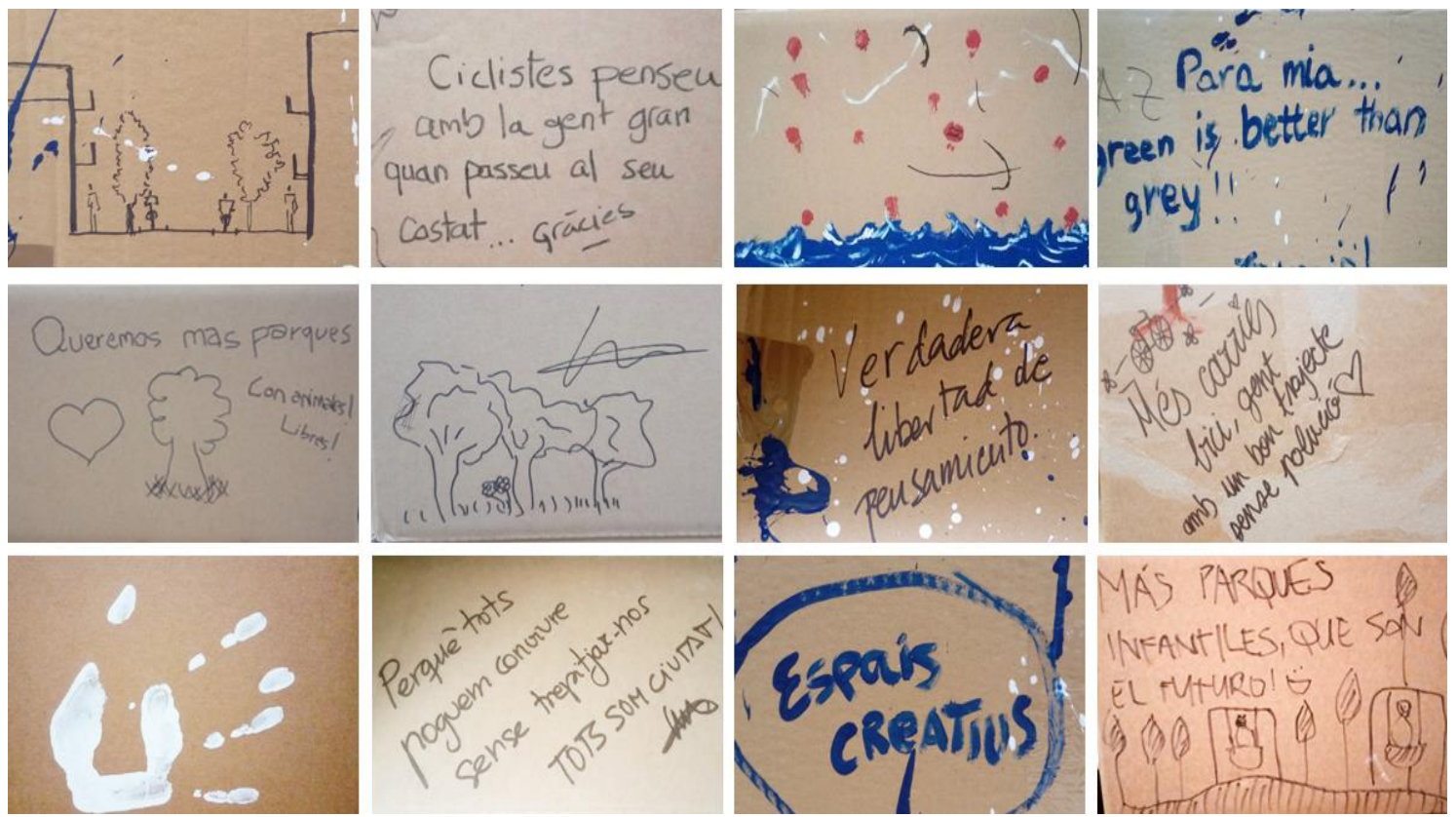

Fotografías: elaboración propia.

${ }^{17}$ A continuación, algunas etiquetas se encuentran referenciadas en el texto. 
Figura 8. Formas de expresión de los mensajes

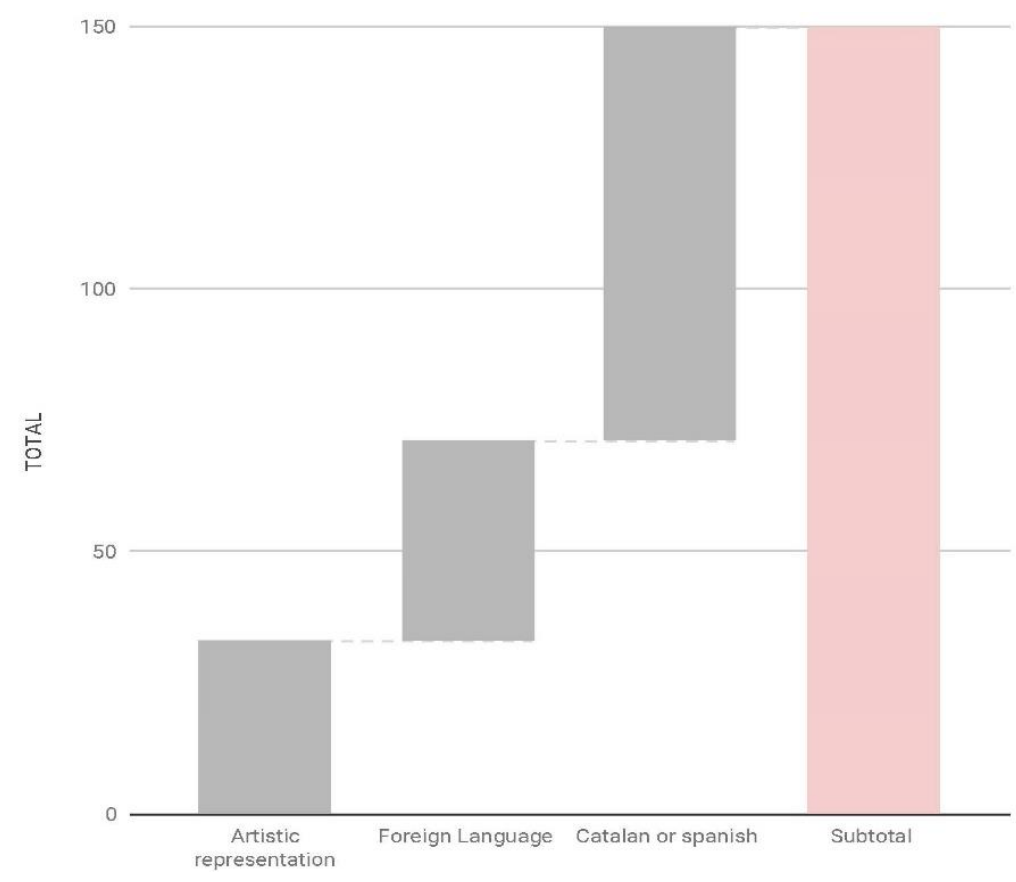

Fuente: elaboración propia.

Figura 9. Deseos catalogados por temas

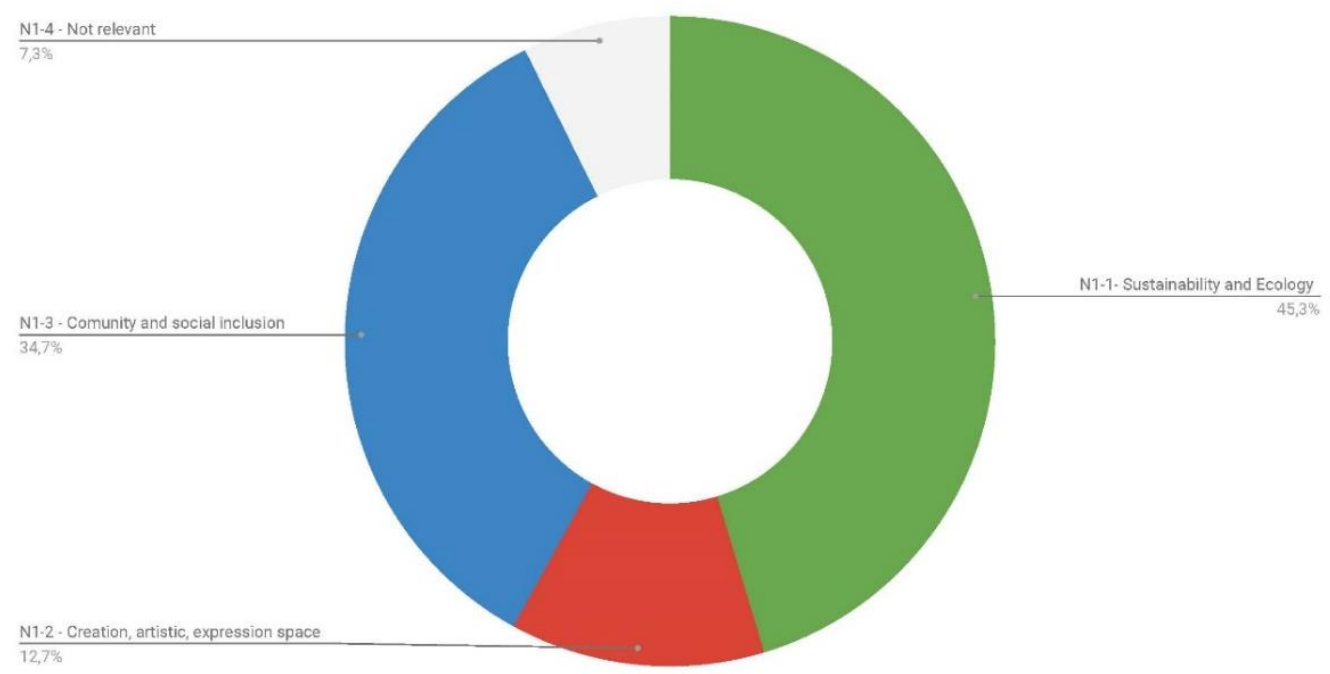

Fuente: elaboración propia.

- N1-1- Sostenibilidad y ecología / Sustainability and Ecology

En el momento en que el alumnado invitó a pasar al pabellón, explicó por supuesto a las mujeres y a los hombres participantes que debían expresarse sobre el futuro de Barcelona, pero enfocó la atención en los espacios públicos y la relación que existe entre el mal uso del espacio urbano por la ocupación de los vehículos privados. Por esta razón, no es sorprendente que la mayoría de los 
mensajes fueron relacionados con la sostenibilidad y la ecología, aunque destaca una voluntad real de una ciudad con mayores espacios verdes (44,1\%), mensajes muy específicos de recuperación de parques familiares, con fauna y flora autóctona ${ }^{18}$. Si interpretamos estos mensajes, obtenemos un manifiesto claro: Un espacio público con suelos permeables y una renaturalización abundante. Algunas impresiones hacen referencia también al estado degradado de la ciudad ${ }^{19}$. Sobre este tema, poco menos de un tercio $(29,4 \%)$ de las personas participantes expresó su deseo de cambiar la movilidad de la ciudad condal de diversas formas, con representaciones y dibujos de bicicletas y de coches tachados, y reivindicación no solo de la bicicleta, sino también del derecho a un aire puro, y por supuesto la disminución de los vehículos privados motorizados ${ }^{20}$. El transporte público también está en cuestión (11,8\%), con algunas peticiones a medio y largo plazo, con la mejora de comunicaciones a municipios, o peticiones a corto plazo de acabar obras, actualmente paradas ${ }^{21}$. Finalmente, el resto de los mensajes (14,7\%) representados o escritos están relacionados con visiones más generales sobre el cuidado del planeta y la ecología.

Figura 10. Sostenibilidad y ecología. Gráficos de deseos con los subtemas

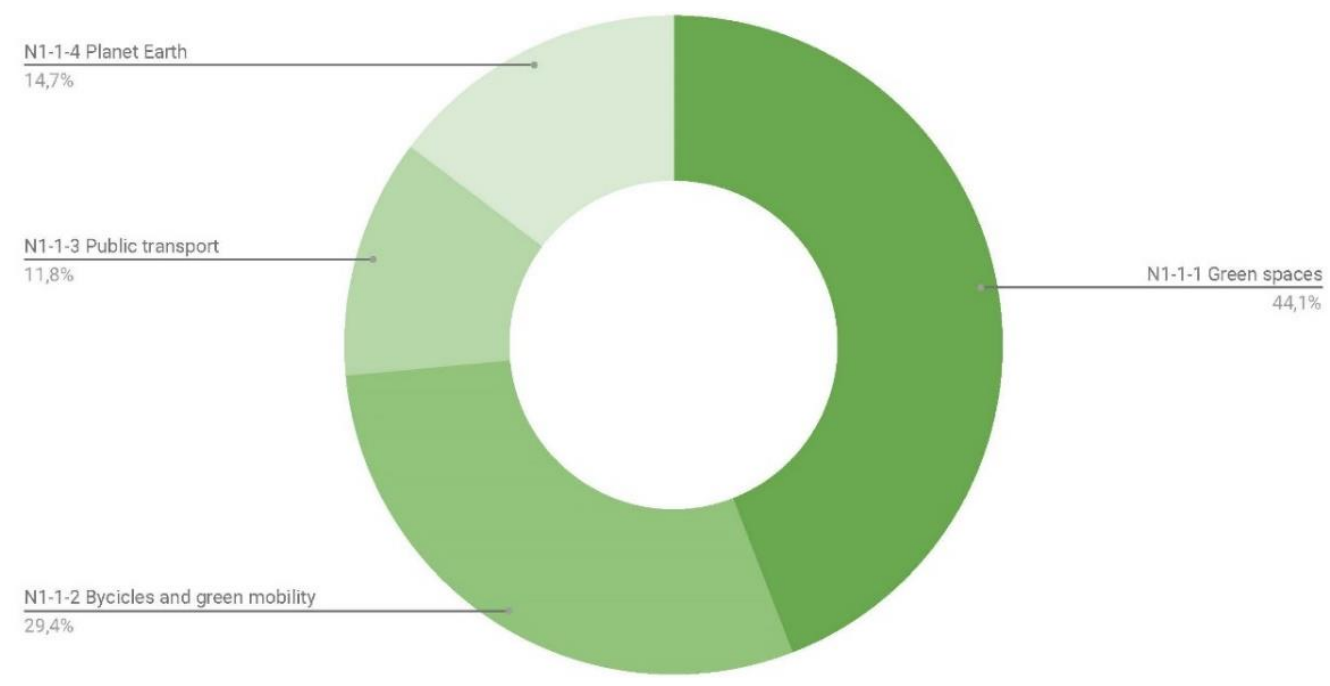

Fuente: elaboración propia.

\section{- N1-2 - Espacios de creación y expresión colectiva}

El pabellón de deseos inspira a la gente, y en algunas interlocuciones con participantes, nos explicaron que desean espacios para expresarse, citando como ejemplo el jardín de las tres chimeneas, diseñado por Pere Riera y Josep Maria Gutiérrez. Aquel espacio tiene, entre otras cosas, muros para grafitis, un escenario, etc. Lo expresan también en el pabellón de diversas formas ${ }^{22}$, con reivindicación de lugares para la expresión artística, creación musical. Y si en ocasiones no estaba formulada explícitamente, el ambiente creativo lo demostró a lo largo del día, con numerosas representaciones artísticas de diversas formas, hojas de árbol caídas pintada de blanco, grafitis,

\footnotetext{
18 \#Más espacios verdes (6 veces), \# + Zona verde - Coches (2 veces), \#Parques, \#Queremos más parques con animales libres, \#Más zonas para pasar en la familia y con nuestras mascotas, \#Más parques infantiles, que son el futuro, representaciones varias de bosques, vegetación exhuberante con animales e insectos varios.

19 \#Sóc de Girona i cada cop que vinc a Barna trobo més i més cotxes. Visquen els espais verds.

20 \#Més carrils bici, gent amb un bon trajecte, sense pol-lució, \#Menys cotxes i més bicicletes, \#+ bicicleta Smart city. El transporte eléctrico 100\%, \# + Bicis eléctricas, - Coches \# More walking, more talking, more park(ing).

21 \#Millora del transport públic, amb optimització de comunicacions a municipis veïns, \#Que acaben las líneas L9, L10, Metro hasta Sardà (y Ripa), \# L11 pls...

22 \#Make art, not war in Barcelona, \#Espais creatius, \#Espacio de música. \#Habitar con la palabra, \#El arte es la herramienta con la que transformamos muerte en vida, \#Luchas x ser arte y crear vida.
}

ACE, 14 (42) CC BY-ND 3.0 ES | UPC Barcelona, España | El pabellón de deseos. Co-creación y co-instalación artística para 14 la mejora del espacio público. DOI: http://dx.doi.org/10.5821/ace.14.42.8200 
collages, poemas, manchas y salpicaduras de colores abstractas dignas del "Action painting" ${ }^{23}$ ocasionadas por gestos vigorosos, pero también apuntes en secciones de mejoras para las calles de Barcelona. Tantas acciones que enseñan a veces una carencia urbana de libertad creativa en el espacio urbano.

\section{- N1-3-Comunidad e inclusión social}

El otro tema más abordado en las visitas del pabellón es el de la sostenibilidad social. Como en los temas ecológicos, hay por supuesto muchos mensajes generales, filantrópicos, pacifistas, de amor y de libertad (38,5\%), pero otros más específicos (28\%) apelan a unos espacios urbanos inclusivos, para la convivencia vecinal y de responsabilidad social ${ }^{24}$. Más allá del espacio público, se desea una nueva gestión del tiempo, con una reducción del horario laboral, para actividades comunitarias, la mejora de la cuestión de la vivienda y una mirada especial hacia la tercera edad. Por supuesto, la cuestión turística está presente, aunque en algunos casos está sugerida de manera sutil y humorística, con la cita de la canción de "Adonde Boy" que retrata de una manera satírica la Barcelona turística ${ }^{25}$.

Figura 11. Comunidad e inclusión social. Gráficos de deseos con los subtemas

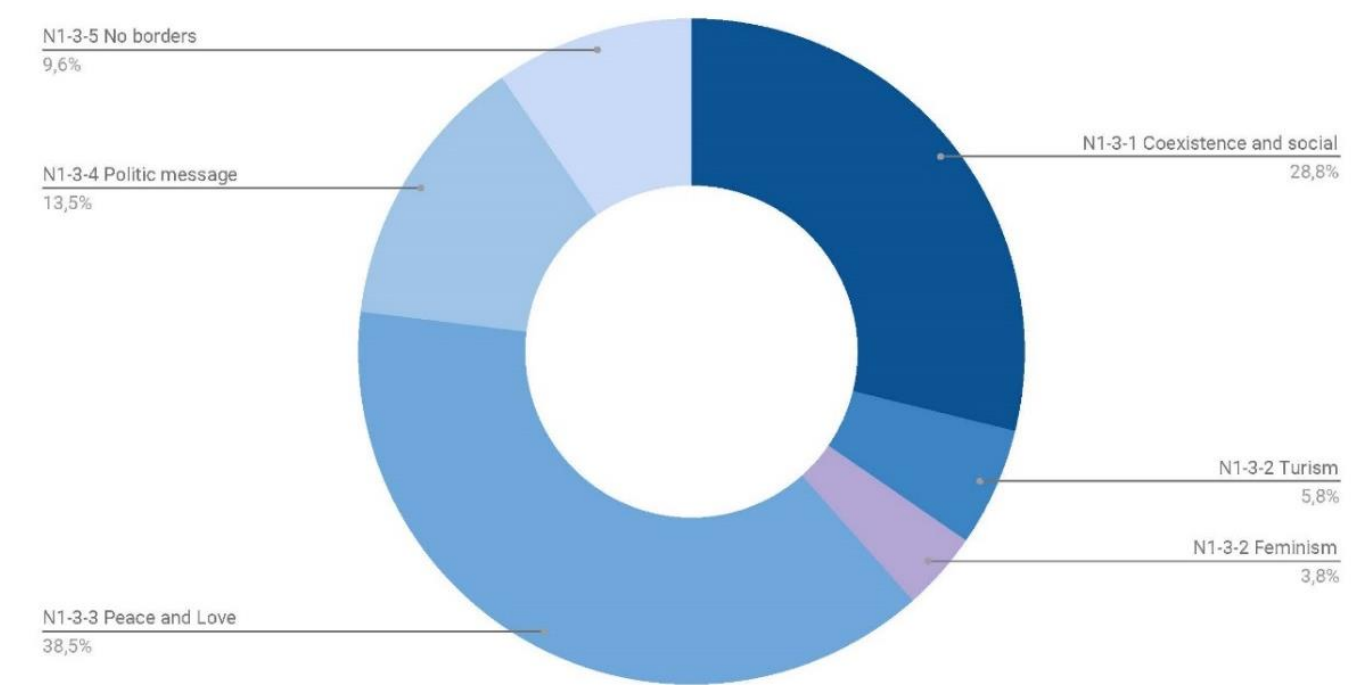

Fuente: elaboración propia.

\section{3 - N2 - Resultados sobre la participación de los estudiantes}

La retroalimentación del taller como herramienta participativa y pedagógica fue evaluada de manera positiva por parte del alumnado, tanto a nivel cualitativo, como a nivel cuantitativo con una valoración alta (N2 - 4,4/5). Los resultados fueron recopilados de dos maneras. La primera, integrando una serie de entrevistas cualitativas con apreciaciones generales sobre el taller, asistencia y nivel de participación voluntaria que permite entender los aspectos, tantos positivos como negativos del taller. Además, tal y como hicimos en la versión anterior del Taller Espacios Abiertos en México, hemos pedido a las y los estudiantes que escriban una opinión y una reflexión, y que nos la entreguen después del taller. Doce estudiantes acudieron al taller de manera

\footnotetext{
${ }^{23}$ Tecnica pictórica que surge en el movimiento del arte moderno abstracto en el siglo XX.

24 \#Perquè tots puguem conviure sense trepitjar-nos. Tots som ciutat!, \#Look after each other. \#Més espais per gaudir els veïns, \#Coordinació dels temps d'estudi i treball, facilitant les activitats esportives i cooperatives, \#Verdadera libertad de pensamiento, \#Facilitació de l'accés a la vivienda i acollida i humanització de les persones sense llar, \# Ciclistes, penseu en la gent gran quan passeu al seu costat...Gràcies, \#Penseu en la gent gran!

25 \# Barcelona, tú lo eres todo con tu yakisoba.
} 
voluntaria, con un interés equilibrado por parte de mujeres y hombres. A medida que se aproximaba el día del taller, el interés fue creciendo, en una atmósfera comunitaria. Según el alumnado, debería haber más proyectos desarrollables a escala 1:1 sobre la base de una problemática urbana real. Describe el taller como intenso, agradable que mezcla varios componentes. La expresión artística fue el punto clave del proceso, junto con la organización en grupo, el proceso sostenible (cero residuos) y la libre interacción entre las personas para formular un proyecto. Se valoró el sentimiento de comunidad e integridad tanto en el proceso creativo entre participantes para llegar a la meta, como en la organización para comunicar con el público. A nivel personal, la fuerza del taller fue trabajar con un grupo diverso, de varias nacionalidades y de varios años académicos. Las expectativas del proyecto fueron superadas, e incluso a veces más, al ver las numerosas personas participando este día. Finalmente, una alumna explica su deseo, de esta ciudad ideal sostenible imaginada y expresada por unas doscientas personas durante el evento.

La segunda manera de registrar los resultados es cuantitativa. Toma forma de cuestionario, con escala de 1 a 5 según el nivel de acuerdo (1 en desacuerdo - 5 totalmente de acuerdo) en relación con las preguntas - N2 - para evaluar el taller.

Figura 12. Resultados y retroalimentación por parte de los estudiantes

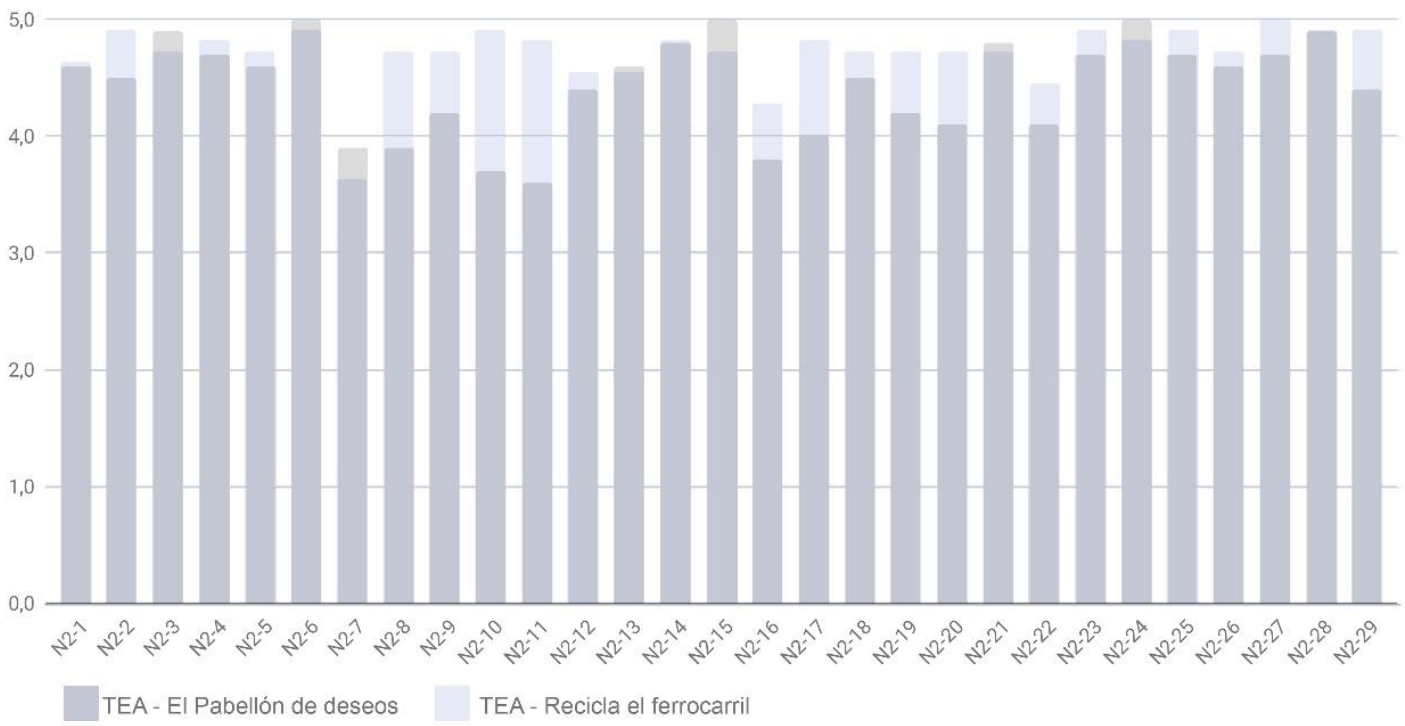

Fuente: elaboración propia.

Así, de esta evaluación, se desprende que el alumnado ve vital involucrar la población (N2-3: 4,9 / 5). Valida la experiencia participativa (N2-5: 4,6/5), la disfruta (N2-23: 4,7/5) y la repetiría de manera voluntaria (N2-28:4,8/5). La califica como exitosa en términos de trabajo grupal (N2-15: 5/5), con buena comunicación entre estudiantes (N2-12: 4,4/5), interés e interacción con el público (N2$22: 4,1 / 5)$. La valida como herramienta en los proyectos urbanos y la pedagogía académica (N2-1 4,6/5). Además del aspecto participativo y el alcance del mensaje, considera que esta experimentación 1/1, y los prototipos les ha permitido entender más sobre arquitectura y estructuras (N2-9: 4,2/5). Aunque la evaluación general es positiva (N2 - 4,4/5), el estudio revela que el tiempo reducido del taller ( 5 días) no permitió considerar que hayan adquirido muchos más conocimientos sobre la sostenibilidad y la ecología (N2-16 - 3,8/5).

Si comparamos la experiencia del pabellón de deseos con la experiencia previa del "TEA: Recicla el Ferrocarril", podemos observar resultados bastante similares, aunque la primera tiene un resultado 
un poco más alto en todos los aspectos. (Figura 12). Esto se debe seguramente, a que aquella experiencia tuvo una duración de 8 meses, por lo que se pudo profundizar mucho más en los temas. Tanto la encuesta de la presente experiencia como la experiencia anterior enseña cómo los estudiantes anhelan tener la experiencia de un curso académico completo usando este método (N2-25 - 4,7/5) y (N2*-25 - 4,9/5). En la experiencia de 8 meses, el cuerpo estudiantil enfatizó bastante más sobre los vínculos humanos que se formaron y el aspecto comunitario del equipo, haciendo referencia al lugar de la intervención como su hogar y a sus camaradas como su familia. Podemos interpretar que el proyecto de co-creación puede volverse transformador social y creador de comunidad si por supuesto le dejamos el tiempo necesario.

\section{Conclusión, análisis crítico de las limitaciones y posibles vías de desarrollo futuro}

Está claro que la integración de los talleres de co-creación y co-construcción como herramienta participativa y pedagógica en los procesos urbanísticos ha generado una retroalimentación positiva. La involucración de este tipo de herramientas artísticas, con una participación doble, a dos niveles, a nivel estudiantil y ciudadana, tiene un interés mayor y permite un círculo virtuoso: (1) el aprendizaje del alumnado en varias materias del grado de arquitectura de una manera alternativa, en equipo y actuando en el espacio público y (2) la interacción directa con la población y su participación activa en el proyecto.

Más allá del aspecto metodológico, uno de los objetivos de este tipo de investigación ha sido el de enseñar cómo se pueden crear dinámicas participativas dirigidas a la escala de barrio de una manera creativa, y responder con soluciones a los problemas ligados con el desaprovechamiento del espacio urbano en Barcelona.

En este sentido, la implementación de este tipo de talleres en el espacio urbano pueden ser métodos para transformar la ciudad de manera paulatina, y aunque la intervención sea efímera, permite preparar a la ciudadanía, hasta una reordenación urbana definitiva. Las personas participantes son receptivas y conscientes de la evolución a un nuevo paradigma gracias a la instalación urbana. Los resultados la identifican como una herramienta divertida y atractiva, que, adaptada a otras situaciones urbanas, puede ser moldeada y combinada fácilmente con la participación de estudiantes, o directamente aplicada con la comunidad local. No obstante, hace falta recalcar las limitaciones de la experiencia del Pabellón de Deseos. Si bien se ha podido generar una actividad participativa con una dimensión artística y comunitaria de lo más interesante, la recogida de información como objetivo de diagnosticar necesidades es limitada. No se ha podido por ejemplo recoger información de las personas que participan como las edades, sexo etc. En el caso del taller de 8 meses de México, fue la actividad de bricolaje urbano, la que permitió generar interés de la comunidad local, creando un espacio creativo generando conversaciones, puntos de vista, reivindicaciones e intervenciones en el lugar. En este sentido, estas dos experiencias del Taller Espacios Abiertos deben ser comprendidas como herramientas participativas de intervención directa, generadoras de conversación participativa, más que una recogida rigurosa de información de diagnóstico sobre necesidades de la población, a la imagen de los trabajos, por ejemplo, del Collectiu Punt6. Se trata entonces de una posible vía de desarrollo futuro para los talleres de cocreación con el cuerpo estudiantil.

Esta experiencia, que sigue la investigación empezada en Oaxaca de Juárez, México, puede ser una manera de proponer, finalmente, una nueva línea de enseñanza de Arte, Arquitectura y Urbanismo, con un método holístico que implica, de alguna manera todas las facetas del trabajo de la 
arquitectura, y mucho más ${ }^{26}$. Porque como bien lo apuntan Zaida Muxí Martínez y Blanca Gutiérrez Valdivia en uno de los libros más influyentes de la historia del urbanismo participativo 27: "la construcción de la ciudad futura se ha de nutrir de diversidad y complejidad, de una práctica inclusiva que incorpore las múltiples variables de la realidad, basándose en un urbanismo de abajo a arriba."

\section{Agradecimientos}

Esta investigación ha sido apoyada por el Programa Estatal de Investigación, Desarrollo e Innovación orientada a los Retos de la Sociedad con referencias BIA2016-77464-C2-1-R y BIA2016-77464-C2-2R. Ambas del Plan Nacional para Investigación científica, desarrollo e innovación tecnológica 20132016, del Gobierno de España.

\section{Autoría}

El primer autor, ha conceptualizado, diseñado y escrito la investigación y el segundo autor (director de la tesis doctoral) ha organizado el trabajo y ha aportado numerosas aclaraciones al mismo.

Conflicto de intereses: Los autores declaran que no hay conflicto de intereses.

\section{Bibliografía}

[AustDoc]. (2012). CPF Canberra Transport Photo, 2012. [Archivo de video]. Recuperado de: https://www.youtube.com/watch?v=YEVaP-W4Vs4

Ayuntamiento de Barcelona (2018). Recuperado de:

https://ajuntament.barcelona.cat/qualitataire/ca/noticia/menys-contaminacize-i-menys-soroll-el-

dia-sense-cotxes

Busquets, J. (2004). Barcelona, La construcción urbanística de una ciudad compacta. Barcelona, España: Ediciones del Serbal, S.A.

Bikehub. (2012). Münster's iconic 'waste of space' photo keeps on giving, 2012. Recuperado de: http://www.bikehub.co.uk/news/sustainability/iconic-waste-of-space-photo-keeps-on-giving

Col-lectiu Punt6. (2017a). Nocturnas. La vida cotidiana de las mujeres que trabajan de noche en el Área Metropolitana de Barcelona. Barcelona, España. Recuperada de https://www.youtube.com/channel/UCaxk-EgP446rMT8avN-s-iQ

Col-lectiu Punt6. (2017). Entornos habitables. Auditoria de seguridad urbana con perspectiva de género en la vivienda y el entorno. Barcelona, España. Colllectiu Punt6.

Collectiu Punt6. (2014a) Espacios para la vida cotidiana. Auditoría de Calidad Urbana con perspectiva de Género. Barcelona, España. Colllectiu Punt6.

\footnotetext{
26 Las guías propias del Collectiu Punt6 permiten generar diagnósticos urbanos inclusivos, con metodologías participativas. Ver por ejemplo: Nocturnas. La vida cotidiana de las mujeres que trabajan de noche en el Área Metropolitana de Barcelona (2017), Entornos habitables. Auditoría de seguridad urbana con perspectiva de género en la vivienda y el entorno (2017), Espacios para la vida cotidiana. Auditoría de Calidad Urbana con perspectiva de Género (2014), Mujeres trabajando. Guía de reconocimiento urbano con perspectiva de género (2014).

27 Jacobs, 2011.
} 
Col-lectiu Punt6. (2014). Mujeres trabajando. Guía de reconocimiento urbano con perspectiva de género. Barcelona, España. Colllectiu Punt6.

Cirugeda S. (2008) Situaciones urbanas, Editorial. Tenov.

De la Peña, D. (2016). Barcelona's Superilles hit a snag, 2016. Recuperado de: https://daviddelapena.com/2016/11/23/superilles/

De la Peña, D. (2017). Design as Democracy, Island Press Paperback Original.

De Carlo, Giancarlo. (1972). An Architecture of Participation. South Melbourne, Australia: Royal Institute of Architects.

Delgado, M. (2007). La ciudad mentirosa, fraude y miseria del modelo. Barcelona, España: ed. Catarata.

Delprat É., YA+K \& Bascop N. (2016). Manuel illustré de bricolage urbain. Paris: Alternatives.

Diputació de Barcelona. (2011). Urbanisme i participació, iniciativa i reptes de futur.

Domingo i Clota M., Bonet I Casas M. (1998). Barcelona i els moviments socials urbans. Barcelona: Editorial Mediterrània.

El Periódico. (2009). La contaminación atmosférica causa 3.500 muertes anuales en el área metropolitana, según un estudio. Recuperado de http://www.elperiodico.com/es/barcelona/20090728/la-contaminacion-atmosfericacausa-3500muertes-anuales-en-el-area-metropolitana-segun-un-estudio-121699

Gehl, J. \& Svarre, B. (2013). How to study public life. Washington D.C: Island Press.

Groundplay. (2017). When imagination goes public. Recuperado de: https://groundplaysf.org/

Instituto de Estadística de Cataluña. (2019). Recuperado de: https://www.idescat.cat/

Illich, I. (1978). Toward a History of Needs, Pantheon Books.

Lefebvre, H. (2017). El derecho a la ciudad. Editorial Capitan Swing, (reedición). (Edición original: 1968)

Jacobs, J. (2011). Muerte y Vida de las grandes ciudades. Madrid: Capitán Swing.

LaCol. (2018). Construir en colectivo, Barcelona: pol-len.cat.

Sánchez-Sepúlveda, M.; Fonseca, D., Franquesa, J.; Redondo, E. (2019), Virtual interactive innovations applied for digital urban transformations. Mixed approach. Future Generation Computer Systems, Volume 91, February 2019, Pages 371-381. DOI: https://doi.org/10.1016/j.future.2018.08.016

Miralles-Guasch, C. (2011). Dinámicas metropolitanas y tiempos de la movilidad. La región metropolitana de Barcelona, como ejemplo. Anales de Geografía, 31 (1), 125-145.

Muxí, Z. (2018). Mujeres, Casas y Ciudades. Más Allá del Umbral. Barcelona, España: Ediciones DPRBARCELONA. 
Parkingdaybarcelona. (2018). Recuperado de: http://parkingdaybcn.org/

Sève B. (2012). Taller Espacios Abiertos, Reciclar el Ferrocarril. Oaxaca de Juárez: UABJO (Universidad Autónoma Benito Juárez).

[StudGM]. (2010). Myndum borg (Picture a City...), 2010. [Archivo de video]. Recuperado de https://www.youtube.com/watch?time continue $=155 \& v=m z n k Z 7 W u J v c$

Sustainable urban transport. (2013). La capital alemana de las bicicletas Münster - el lugar donde el corazón de un ciclista late más tiempo. Recuperado de: https://www.sutp.org/es/news-reader/lacapital-alemana-de-las-bicicletas-mnster-el-lugar-donde-el-corazn-de-un-ciclista-late-mstiempo.html

Swanson, A. (2015). One image shows what cities would look like without cars. The Washington Post, Recuperado de https://www.washingtonpost.com/news/wonk/wp/2015/08/10/what-cities-wouldlook-like-without-cars/?noredirect=on\&utm term=.22950ec822f1

WWF. (2018). OSCS realizan Desafío Modal 2018 en la Ciudad de México: por la seguridad de todos los usuarios de la vía. Recuperado de http://www.wwf.org.mx/?uNewsID=335130 